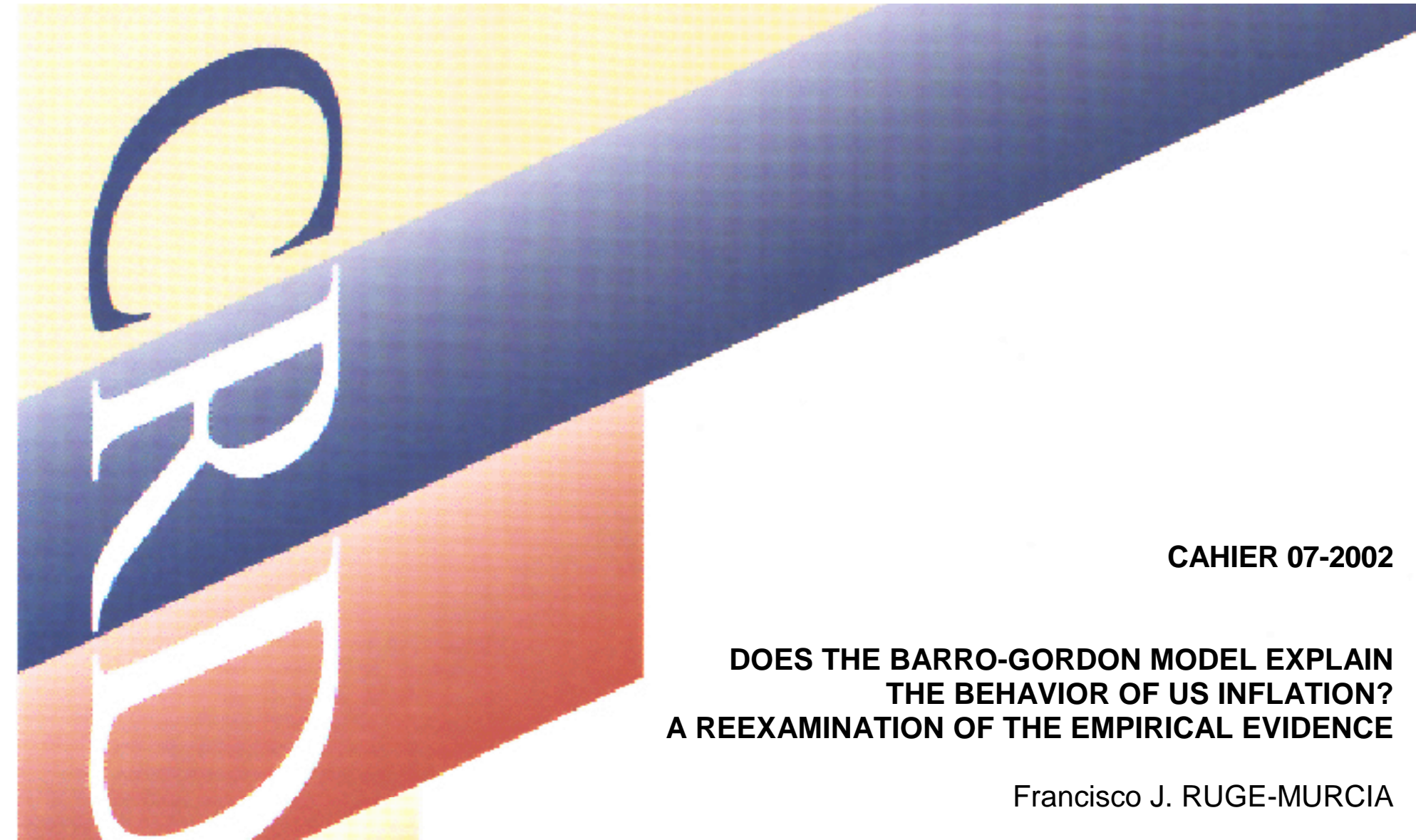

Centre de recherche et développement en économique

C.P. 6128, succursale Centre-ville Montréal QC H3C 3J7

Téléphone : (514) 343-6557

Télécopieur : (514) 343-5831

crde@crde.umontreal.ca

http://www. crde. umontreal.ca/

\author{
Université th \\ de Montréal
}


CAHIER 07-2002

\title{
DOES THE BARRO-GORDON MODEL EXPLAIN THE BEHAVIOR OF US INFLATION? A REEXAMINATION OF THE EMPIRICAL EVIDENCE
}

\author{
Francisco J. RUGE-MURCIA ${ }^{1}$
}

1 Centre de recherche et développement en économique (C.R.D.E.) / Centre interuniversitaire de recherche en économie quantitative (CIREQ) and Département de sciences économiques, Université de Montréal

May 2002

All programs and data employed are available from the author upon request. Financial support from the Social Sciences and Humanities Research Council of Canada and the Fonds pour la formation de chercheurs et l'aide à la recherche of Québec is gratefully acknowledged. 


\section{RÉSUMÉ}

Ce papier teste les prédictions du modèle de Barro-Gordon en utilisant les données américaines sur l'inflation et le chômage. Pour ce faire, il construit un modèle de jeu théorique général avec des préférences asymétriques qui englobe le modèle de Barro-Gordon et une version du modèle de Cukierman qui sont des cas spéciaux. Les tests du rapports de vraisemblance indiquent que la restriction imposée par le modèle de Barro-Gordon est rejetée par les données, mais celle imposée par la version du modèle de Cukierman ne l'est pas. Les estimations sous la forme réduite sont cohérentes avec l'idée selon laquelle la Réserve fédérale accorde une plus grande importance aux déviations positives qu'aux déviations négatives du chômage par rapport au taux naturel espéré.

Mots clés : préférences asymétriques, prudence, modèles de théories des jeux avec politique monétaire, $\mathrm{ARCH}$

\section{ABSTRACT}

This paper tests the predictions of the Barro-Gordon model using US data on inflation and unemployment. To that end, it constructs a general game-theoretical model with asymmetric preferences that nests the Barro-Gordon model and a version of Cukierman's model as special cases. Likelihood Ratio tests indicate that the restriction imposed by the Barro-Gordon model is rejected by the data but the one imposed by the version of Cukierman's model is not. Reduced-form estimates are consistent with the view that the Federal Reserve weights more heavily positive than negative unemployment deviations from the expected natural rate.

Key words : asymmetric preferences, prudence, game-theoretical models of monetary policy, $\mathrm{ARCH}$ 


\section{Introduction}

In an important article in the Journal of Monetary Economics, Ireland (1999) examines whether the time-inconsistency problem in Barro and Gordon (1983) can explain the behavior of the US inflation rate. Although the data rejects the predictions on the short-run dynamics of inflation and unemployment, it upholds the prediction on the long-term dynamics whereby these variables form a linear and positive cointegrating relation. An interpretation of the time-inconsistency problem in Barro and Gordon is that the inflation bias arises because the central banker is too ambitious, in the sense that it targets a rate of unemployment below the natural rate. This assumption has been challenged recently on both theoretical and operational grounds. McCallum (1997) argues that since, in equilibrium, unemployment equals the natural rate but inflation is larger than optimal, the central banker would eventually understand that the unemployment target is unobtainable and revise its goal. Blinder (1998) suggests on the basis of institutional evidence, that central banks actually target the expected natural rate of unemployment. However, relaxing this assumption in the linear-quadratic framework of Barro and Gordon means that the inflation bias is zero and the model cannot explain suboptimally high inflation rates as arising from the lack of a commitment technology.

More recently, Cukierman (2000) constructs a model where the central banker has asymmetric unemployment preferences. Preferences are asymmetric in that the loss is zero for negative, but increases quadratically for positive, unemployment deviations from the target. Cukierman shows that if the central banker is uncertain about the future realizations of inflation and unemployment, then an inflation bias can arise even if the unemployment target is the natural rate. Ruge-Murcia (2001) examines empirically this proposition using data from six developed economies and a specification of preferences whereby the central banker can attach a larger weight to positive than negative unemployment deviations from the natural rate. The functional form employed by Ruge-Murcia is attractive because it nests the usual quadratic loss function as a special case.

This paper constructs a general model with asymmetric preferences and an unemployment target that is proportional to the natural rate. This model nests as special cases the Barro-Gordon model and the version of Cukierman's model examined by Ruge-Murcia (2001). A linearized, reduced-form version of the model predicts that inflation depends on expected unemployment (as in the Barro-Gordon model) and the conditional variance of unemployment. When the unemployment target is the natural rate, the coefficient on expected unemployment is zero and Cukierman's model is obtained. When the preference parameter takes the value corresponding to a quadratic loss function, the coefficient on the 
conditional variance is zero and the Barro-Gordon model is obtained.

The model is estimated using quarterly US data on inflation and unemployment. Likelihood Ratio tests indicate that the restriction imposed by the Barro-Gordon model is rejected by the data but the one imposed by Cukierman's model is not. These results are robust to the forecasting model for unemployment and to the sample period employed. Hence, the behavior of US inflation appears to be better explained by a model where the central banker has asymmetric unemployment preferences around the expected natural rate, than by the standard textbook Barro-Gordon model with quadratic preferences and an unemployment target below the natural rate.

Although the asymmetry preference parameter cannot be identified from the reducedform coefficients, results are consistent with the view that the Federal Reserve weights more heavily positive than negative unemployment deviations from the natural rate. This result could explain the finding reported by Dolado et al. (2000) that, measured in terms of changes to the Federal Funds rate, the Federal Reserve appears to react more strongly to negative than positive output gaps.

The paper is organized as follows. Section 2 formulates and solves the game-theoretical model. Section 3 describes the data, constructs the reduced-form version of the model, and reports econometric results. Section 4 concludes.

\section{The Model}

\subsection{Basic Setup}

Following the literature, an expectations-augmented Phillips curve relates inflation $\left(\pi_{t}\right)$, unemployment $\left(u_{t}\right)$, and the natural rate of unemployment $\left(u_{t}^{n}\right)$ :

$$
u_{t}=u_{t}^{n}-\lambda\left(\pi_{t}-\pi_{t}^{e}\right)+\eta_{t}
$$

where $\lambda$ is a strictly positive coefficient, $\pi_{t}^{e}$ is the public's forecast of inflation at time $t$ constructed at time $t-1$, and $\eta_{t}$ is a supply disturbance. The public's forecasts are constructed rationally, meaning that:

$$
\pi_{t}^{e}=E_{t-1} \pi_{t},
$$

where $E_{t-1}$ is the expectation conditional on all information available at time $t-1$. In what follows, I denote the public's information set at time $t-1$ by $I_{t-1}$, and assume that it includes all model parameters and observations of the variables up to and including period $t-1$. 
The natural rate of unemployment evolves over time according to:

$$
\Delta u_{t}^{n}=\psi-(1-\delta) u_{t-1}^{n}+\theta \Delta u_{t-1}^{n}+\zeta_{t}
$$

where $\zeta_{t}$ is an innovation. This process includes as special cases the stationary $(0<\delta<1)$ and unit root $(\delta=1)$ models of the natural rate employed in earlier literature. ${ }^{1}$ The intention here is to adopt a general time series specification for the natural rate and then examine to what extent results are robust to different forecasting models for $u_{t}^{n}$. The process (3) represents the idea that exogenous changes in technology and labor force demographics, among others, could affect the labor market and generate movements in the natural rate. Evidence that the natural rate in the United States has changed over the postwar period is reported by Weiner (1993), Tootell (1994), and Staiger, Stock, and Watson (1997).

The central banker affects the inflation rate through a policy instrument. The instrument is imperfect in that it cannot determine inflation completely, as in:

$$
\pi_{t}=i_{t}+\epsilon_{t}
$$

where $i_{t}$ is the policy instrument and $\epsilon_{t}$ is a control error. This simple specification relaxes the usual assumption that the monetary authority chooses directly the rate of inflation after observing (before the public does) the random shocks. Since there is no private information in the model, the central banker's information set coincides with the public's. ${ }^{2}$

Define $\boldsymbol{\xi}_{t}$ to be the $3 \times 1$ vector that contains the model's structural shocks at time $t$. I assume that $\boldsymbol{\xi}_{t}$ is serially uncorrelated, normally distributed with zero mean, and (possibly) conditionally heteroskedastic:

$$
\boldsymbol{\xi}_{t}\left|I_{t-1}=\left[\begin{array}{c}
\eta_{t} \\
\zeta_{t} \\
\epsilon_{t}
\end{array}\right]\right| I_{t-1} \sim N\left(\mathbf{0}, \boldsymbol{\Omega}_{t}\right),
$$

where $\Omega_{t}$ is a $3 \times 3$ positive-definite variance-covariance matrix. The conditional heteroskedasticity of $\boldsymbol{\xi}_{t}$ relaxes the more restrictive assumption of constant conditional second moments and captures temporary changes in the volatility of the structural shocks. For example, Hamilton (1996, figure 2) shows that the net change in nominal oil prices, that could be assimilated to a supply shock, appears to have been more variable in the 1970s than in the 1960 s or the 1980 s.

\footnotetext{
${ }^{1}$ The constant term could have been written as $\psi(1-\delta)$ in order to rule out a drift when unemployment is $I(1)$. However, for the estimation of the model, it is desirable to allow a nonzero intercept. Standard procedures can then be used to test whether this term is significantly different from zero.

${ }^{2}$ As an alternative to (4), one could postulate an aggregate demand relation [for example as in Orphanides and Wilcox (1996)]. In this case, the model solution is unchanged but the interpretation of the reduced-form disturbances is slightly different.
} 
The central banker has additively separable preferences over inflation and unemployment. Preferences are represented by the function:

$$
C\left(\pi_{t}, u_{t}\right)=(1 / 2)\left(\pi_{t}-\pi_{t}^{*}\right)^{2}+\left(\phi / \gamma^{2}\right)\left(\exp \left(\gamma\left(u_{t}-u_{t}^{*}\right)\right)-\gamma\left(u_{t}-u_{t}^{*}\right)-1\right),
$$

where $\gamma \neq 0$ and $\phi>0$ are preference parameters, and $\pi_{t}^{*}$ and $u_{t}^{*}$ are the desired rates of inflation and unemployment, respectively. The possibly nonzero $\pi_{t}^{*}$ could interpreted, for example, as the one associated with the optimal inflation tax. As in Ireland (1999), the socially-optimal inflation rate is assumed stable enough to be well approximated by a constant term (denoted by $\pi^{*}$ below).

The unemployment component in (5) is described by the linex function $g(x)=(\exp (\gamma x)-$ $\gamma x-1) / \gamma^{2}$ [Varian (1974)]. ${ }^{3}$ This function has several important properties. First, it permits different weights for positive and negative unemployment deviations from the target. Consider the case where $\gamma>0$. For unemployment rates below the target, the linear term becomes progressively more important as unemployment decreases and, consequently, the loss rises linearly. For unemployment rates above the target, it is the exponential term that eventually dominates and the loss associated with a positive deviation rises exponentially. Hence, positive deviations from the target are weighted more severely than negative ones in the central banker's loss function. A possible interpretation of this feature is that it represents different attitudes vis a vis expansions and recessions on the part of the central banker. Second, it predicts that both the size and sign of a deviation affect the central banker's loss. In contrast, under quadratic preferences, the loss is completely determined by the size of the deviation. Third, it relaxes certainty equivalence and allows a prudence motive on the part of the central banker. Then, moments of higher order than the mean might play a role in the formulation of monetary policy. For this loss function, the coefficient of relative prudence [see Kimball (1990)] is $\gamma\left(u_{t}-u_{t}^{*}\right)$, that is directly proportional to the unemployment deviation from its target and increasing in $\gamma$. Fourth, it is analytically tractable and yields a closed-form solution when shocks are normally distributed (see below). Finally, it nests the quadratic function commonly used in previous literature as a special case when the preference parameter $\gamma$ tends to zero. ${ }^{4}$ This result is important because it suggests that the

\footnotetext{
${ }^{3}$ To my knowledge, this loss function was first employed in monetary policy games by Nobay and Peel (1998). Zellner (1986), Granger and Pesaran (1996), and Christoffersen and Diebold (1997) study this function in the context of optimal forecasting.

${ }^{4}$ Formally,
}

$$
\operatorname{Lim}_{\gamma \rightarrow 0} \frac{\exp (\gamma x)-\gamma x-1}{\gamma^{2}}=\operatorname{Lim}_{\gamma \rightarrow 0} \frac{x \exp (\gamma x)-x}{2 \gamma}=\operatorname{Lim}_{\gamma \rightarrow 0} \frac{x^{2} \exp (\gamma x)}{2}=\frac{x^{2}}{2} .
$$


hypothesis that the central banker's preferences are quadratic over unemployment could be evaluated by testing whether $\gamma$ is statistically different from zero or not.

The rate of unemployment targeted by the central banker is proportional to the expected natural rate of unemployment:

$$
u_{t}^{*}=k E_{t-1} u_{t}^{n}, \quad 0<k \leq 1
$$

It is important to note that (6) admits two special cases. First, the unemployment target can be strictly less than the expected natural rate (that is, $0<k<1$ ). Persson and Tabellini (2000) note that this assumption is essential in generating the inflation bias in the linear-quadratic framework of Kydland and Prescott (1977) and Barro and Gordon (1983). Second, the unemployment target can equal the expected natural rate (that is, $k=1$ ). Blinder (1998) argues that this can be a good description of the central bankers' behavior.

\subsection{Solution}

At time $t-1$, the central banker selects the value of the instrument, $i_{t}$, that minimizes her expected loss function. The minimization is subject to the expectations-augmented Phillips curve and takes as given the public's inflation forecast. The first-order necessary condition of this problem is

$$
E_{t-1} \pi_{t}-\pi^{*}-(\lambda \phi / \gamma) E_{t-1}\left(\exp \left(\gamma\left(u_{t}-k E_{t-1} u_{t}^{n}\right)\right)-1\right)=0
$$

Since the objective function is globally convex, the solution to this equation delivers a unique minimum. As shown below, the assumption that the structural disturbances are normal implies that, conditional on the information set, unemployment is also normally distributed. Then, $\exp \left(\gamma\left(u_{t}-k E_{t-1} u_{t}^{n}\right)\right)$ is distributed log normal. Using the intermediate result

$$
E_{t-1} u_{t}=E_{t-1} u_{t}^{n}
$$

obtained by taking conditional expectations in both sides of (1) and using the assumption of rational expectations, it is possible to write the mean of this log normal distribution as $\left.\exp \left(\gamma(1-k) E_{t-1} u_{t}^{n}+\gamma^{2} \sigma_{u, t}^{2} / 2\right)\right)$. The notation $\sigma_{u, t}^{2}$ is the conditional variance of unemployment and is derived below in terms of the elements of $\boldsymbol{\xi}_{t}$. Finally, using eq. (4), it is easy to show that

$$
\pi_{t}=\pi^{*}+(\lambda \phi / \gamma)\left(\exp \left(\gamma(1-k) E_{t-1} u_{t}^{n}+\gamma^{2} \sigma_{u, t}^{2} / 2\right)-1\right)+\mathbf{A} \boldsymbol{\xi}_{t}
$$

and

$$
u_{t}=E_{t-1} u_{t}^{n}+\mathbf{B} \boldsymbol{\xi}_{t}
$$


where $\mathbf{A}=(0,0,1)$ and $\mathbf{B}=(1,1,-\lambda)$. Note that since $E_{t-1} u_{t}^{n}$ is included in the public's information set at time $t-1$ and the linear combination $\mathbf{B} \boldsymbol{\xi}_{t}$ is normally distributed, then

$$
u_{t} \mid I_{t-1} \sim N\left(E_{t-1} u_{t}^{n}, \sigma_{u, t}^{2}\right)
$$

where $\operatorname{Var}\left(u_{t} \mid I_{t-1}\right)=\sigma_{u, t}^{2}=\mathbf{B} \Omega_{t} \mathbf{B}^{\prime}$, as claimed above.

\subsection{Two Special Cases}

This model was deliberately designed to include the models by Barro and Gordon (1983), and Cukierman (2000) as special cases. First, when $\gamma \rightarrow 0$ (with $0<k<1$ ), one obtains the Barro-Gordon model:

$$
\pi_{t}=\pi^{*}+\lambda \phi(1-k) E_{t-1} u_{t}^{n}+\mathbf{A} \boldsymbol{\xi}_{t}
$$

Since the expected natural rate is strictly positive and $\lambda \phi(1-k)>0$, the average rate of inflation is above the optimum. This systematic difference between realized and optimal inflation is the inflation bias. Note that if the central banker targets the expected natural rate of unemployment, there is no longer an inflation bias and the model cannot explain suboptimally high rates of inflation as the result of the lack of a commitment technology. From (10), it is clear that the Barro-Gordon model predicts that inflation is positively and linearly related to the expected rate of unemployment.

Second, when $k=1$, one obtains a model that is close in spirit to the one proposed by Cukierman (2000):

$$
\pi_{t}=\pi^{*}+(\lambda \phi / \gamma)\left(\exp \left(\gamma^{2} \sigma_{u, t}^{2} / 2\right)-1\right)+\mathbf{A} \boldsymbol{\xi}_{t}
$$

In this case there can be an inflation bias even if the central banker targets the natural rate of unemployment. This result follows from the observation that $\lambda \phi\left(\exp \left(\gamma^{2} \sigma_{u, t}^{2} / 2\right)-1\right)$ is always positive and $\gamma \neq 0$, by assumption. The sign of the bias depends on whether $\gamma \lessgtr 0$. In the case where $\gamma<0$, there is a deflation bias. In the more plausible case where $\gamma>0$, there is an inflation bias. The bias is proportional to the conditional variance of unemployment. The intuition of this result is as follows. Recall that when the loss function is quadratic, certainty equivalence holds. Then, the solution of the model is the same regardless of whether there is uncertainty or not, and only the first (conditional) moment of unemployment explains the rate of inflation. On the other hand, with asymmetric unemployment preferences, the marginal benefit of surprise inflation is not linear in unemployment, but convex when $\gamma>0$. Thus, an increase in uncertainty raises the expected marginal benefit of surprise inflation.

Equation (11) is not the one derived by Cukierman because he uses a different asymmetric loss function than the one employed here. Cukierman assumes that the loss function is 
quadratic for positive, and zero for negative, unemployment deviations from the expected natural rate. In equilibrium, the inflation bias is an increasing function of the probability that unemployment falls above the natural rate. However, the basic insight that there can be an inflation bias when the central banker targets the natural rate provided that her preferences are asymmetric is due to Cukierman. This Section simply recasts his model in terms of a loss function that includes quadratic preferences as a special case. This is very useful because it means that one can test the Barro-Gordon model against a well defined alternative.

In both the Barro-Gordon model and the version of Cukierman's model developed here there can be an inflation bias that arises from the possible temporal inconsistency of monetary policy in an environment where commitment is not credible. However, the mechanics by which the inflation bias arises are different. In the former model, the bias is due to the central banker's desire to obtain the unattainable: a rate of unemployment below the natural rate. In the latter model, the bias arises from the interaction of prudence and uncertainty. This difference has nontrivial implications in positive and normative terms. In normative terms, the design of institutions (for example, inflation targets or performance contracts) might

be different depending on the underlying origin of the inflation bias. In positive terms, the following section examines whether either of these models (or both) can account for the inflation dynamics in the United States.

\section{Econometric Analysis}

\subsection{The Data Set}

The empirical analysis is carried out using quarterly, seasonally-adjusted observations of US inflation and unemployment. The rate of inflation is measured by the percentage change (on an annual basis) in the GDP deflator. The unemployment rate is measured by the average rate of civilian unemployment in the three months of the quarter. The raw quarterly GDP deflator and the monthly unemployment rate were taken from the Web Site of the US Bureau of Labor Statistics (http://stats.bls.gov). In order to assess the robustness of the results and to allow their comparison with those reported by Ireland (1999), two sample periods are considered, namely 1960:1 to 1999:4 and 1970:1 to 1999:4. The sample ends with latest available observation at the time the data was collected (fall of 2000). 


\subsection{The Reduced-Form}

The empirical analysis of the game-theoretical developed above is complicated by three factors. First, the natural unemployment rate cannot be observed directly. This means that in order to estimate the model using data on inflation and unemployment alone, it is necessary to construct a reduced-form version of the model. ${ }^{5}$ Second, the conditional variance of unemployment cannot be observed directly either. In order to address this problem, one can construct an estimate of $\sigma_{u, t}^{2}$ using, for example, a parametric ARCH-type model. However, since the conditional variance then becomes a generated regressor, one must consider its effect on the efficiency and consistency of the estimates.

Third, it is not possible to recover all structural parameters of the model from the reducedform estimates. In particular, the preference parameter $\gamma$ is not identified. ${ }^{6}$ However, we will see below that the sign of the reduced-form coefficient of $\sigma_{u, t}^{2}$ is informative about the sign of $\gamma$. A simple transformation of the model that confronts directly this problem involves the linearization of the exponential term in (8) by means of a first-order Taylor series expansion and the use of (7) to obtain the reduced-form:

$$
\pi_{t}=a+b E_{t-1} u_{t}+c \sigma_{u, t}^{2}+e_{t}
$$

where $a$ is a constant intercept, $b=\lambda \phi(1-k) \geq 0, c=\lambda \phi \gamma / 2 \lessgtr 0$, and $e_{t}$ is a reducedform disturbance. Notice that even though an estimate of $c$ does not reveal the values of $\lambda, \phi$, and $\gamma$, its sign tell us something about the asymmetry in the central banker's preferences. Specifically, since $\lambda, \phi>0$, a positive estimate of $c$ implies that $\gamma>0$ and is consistent with the idea that the central banker weights more heavily positive than negative unemployment deviations from the target. In terms of the two special cases discussed above, the Barro-Gordon model corresponds to the case where $\gamma \rightarrow 0$ and, consequently, $c=0$. The Cukierman model corresponds to the case where $k=1$ and, consequently, $b=0$.

A reduced-form for the unemployment process is constructed as follows. Use $E_{t-1} u_{t}^{n}=$ $\psi-(1-\delta) u_{t-1}^{n}+\theta \Delta u_{t-1}^{n}$ from (3) and substitute in (9) to obtain:

$$
u_{t}=\psi-(1-\delta) u_{t-1}^{n}+\theta \Delta u_{t-1}^{n}+\zeta_{t}+\eta_{t}-\lambda \epsilon_{t} .
$$

\footnotetext{
${ }^{5}$ Staiger, Stock, and Watson (1997) construct estimates of the natural rate using data on inflation and unemployment. In the context of this model, it is clear that such estimates provide no additional information beyond that already contained in $\pi_{t}$ and $u_{t}$.

${ }^{6}$ To see this, rewrite (8) as

$$
\pi_{t}=\left(\pi^{*}-\lambda \phi / \gamma\right)+(\lambda \phi / \gamma)\left(\exp \left(\gamma(1-k) E_{t-1} u_{t}+\gamma^{2} \sigma_{u, t}^{2} / 2\right)+\mathbf{A} \boldsymbol{\xi}_{t} .\right.
$$

An estimate of the intercept term would only deliver a combination of the structural parameters, namely $\pi^{*}-\lambda \phi / \gamma$, while the time-series variation of $\sigma_{u, t}^{2}$ and $E_{t-1} u_{t}$ alone would not identify $k, \lambda, \phi$ and $\gamma$.
} 
Adding and substracting $\psi+\delta u_{t-1}+\theta \Delta u_{t-1}$, noting that $u_{t}^{n}-u_{t}=\lambda \epsilon_{t}-\eta_{t}$, and substracting $u_{t-1}$ in both sides yield:

$$
\Delta u_{t}=\psi-(1-\delta) u_{t-1}^{n}+\theta \Delta u_{t-1}^{n}+\zeta_{t}-\lambda \epsilon_{t}+\eta_{t}+\delta\left(\lambda \epsilon_{t-1}-\eta_{t-1}\right)+\theta\left(\lambda \Delta \epsilon_{t-i}-\Delta \eta_{t-i}\right)
$$

This equation describes unemployment as a function of its past realizations and a linear combination of current and past structural shocks. An advantage of this representation is that it does not include the unobserved natural rate as one of the regressors. However, with only data on inflation and unemployment, it is not possible to disentangle the residuals of each structural disturbance. This means that one cannot construct empirical counterparts for the lagged $\epsilon_{t}$ and $\eta_{t}$ that enter (13) and, consequently, the unemployment process cannot be estimated without additional identification restrictions.

The strategy followed here assumes that $\zeta_{t}, \epsilon_{t}$ and $\eta_{t}$ are mutually uncorrelated with each other at all leads and lags, and exploits time series results on the aggregation of ARMA processes [see Harvey (1981, p. 43)]. ${ }^{7}$ These results imply that the aggregation of $\zeta_{t}$ and the two $\mathrm{MA}(2)$ processes in $\epsilon_{t}$ and $\eta_{t}$, yields a MA(2) process with exactly the same statistical properties as the original sequence. Hence, in the case where the natural rate of unemployment is assumed to be $I(1)$ (that is, $\delta=1$ ), realized unemployment follows an $\operatorname{ARIMA}(1,1,2)$ process. In the case where the natural rate of unemployment is assumed to be $I(0)$ (that is, $\delta=1$ ), realized unemployment follows an $\operatorname{ARIMA}(2,0,2)$ process.

Finally, from the assumptions about the structural shocks, it follows that the reducedform disturbances are also serially uncorrelated, jointly normally distributed with zero mean, and possibly conditionally heteroskedastic.

\subsection{Econometric Issues}

The model predicts that the conditional variance of unemployment helps forecast the inflation rate. However, this prediction can only be examined in a time series framework if unemployment is conditionally heteroskedastic. That is, if $\sigma_{u, t}^{2}$ changes over time. Otherwise, if $\sigma_{u, t}^{2}$ is constant, its coefficient is not be identified. Hence, before proceeding further, it is important to test whether the conditional variance of unemployment is indeed timevarying. Lagrange Multiplier (LM) test statistics for neglected $\mathrm{ARCH}$ were calculated as the product of the number of observations and the uncentered $R^{2}$ of the OLS regression of

\footnotetext{
${ }^{7}$ This identification strategy is different from that in Ireland (1999). In his case, the Phillips curve has no supply disturbance. With two structural shocks $\left(\zeta_{t}\right.$ and $\left.\epsilon_{t}\right)$ and two observable variables $\left(\pi_{t}\right.$ and $\left.u_{t}\right)$, one can recover the lagged $\epsilon_{t}$ in (13). The model also generates additional covariance restrictions that allow the identification of $\lambda$, but not of $\phi$ or $k$. Ireland reports (p. 287) that these restrictions are rejected by US data.
} 
the squared unemployment residual on a constant and one to six of its lags. Under the null hypothesis of no conditional heteroskedasticity, this statistic is distributed chi-square with as many degrees of freedom as the number of lagged squared residuals included in the regression. The residuals are the ones obtained from fitting an $\operatorname{ARIMA}(1,1,2)$ to the US unemployment rate and are labeled as "original" in Table $1 .{ }^{8}$ Since all statistics are above their 5 percent critical value in all cases, the hypothesis of no conditional heteroskedasticity can be rejected.

Since $\sigma_{u, t}^{2}$ is the conditional variance of unemployment as of time $t-1$ and $e_{t}$ is serially uncorrelated, then $\sigma_{u, t}^{2}$ is contemporaneously uncorrelated with $e_{t}$. However, $\sigma_{u, t}^{2}$ is not directly observable. Instead, I use a $\operatorname{GARCH}(1,1)$ to construct an estimate of the conditional variance. Because this estimate is constructed using unemployment data, it constitutes a generated regressor. Pagan (1984) and Pagan and Ullah (1988) study the implications of generated regressors in estimation and inference. In many cases generated regressors can be problematic because they measure with noise the true, but unobserved, regressor. In the specific case where the conditional variance is computed using an ARCH-type model, the Maximum Likelihood estimator could be biased and inconsistent if the ARCH model is misspecified. Unfortunately, the instrumental variable estimator proposed by Pagan and Ullah cannot be employed in this case because the current endogenous variable is a function of all past history and no instruments are available. Instead, Pagan and Ullah (p. 99) suggest specification tests to assess whether the chosen ARCH model is valid. A standard misspecification test for ARCH models is the LM test for neglected ARCH described above, but applied to the standardized squared residuals. If the ARCH model is correctly specified, then the residuals corrected for heteroskedasticity and squared should be serially uncorrelated. These residuals are label as "standardized" in Table 1. Since all statistics are below their 5 percent critical value in all cases, the hypothesis of no conditional heteroskedasticity cannot be rejected. Hence, it would appear that the parsimonious $\operatorname{GARCH}(1,1)$ model employed here adequately captures the conditional heteroskedasticity in US unemployment.

ARCH models parameterize the conditional variance of a series as a function of lagged squared residuals. In terms of the game-theoretical model here, this means $\sigma_{u, t}^{2}$ is a parametric function of lagged squared unemployment. Then, the comparison between the BarroGordon model and the version of Cukierman's model can be cast in the following terms. Under the Barro-Gordon model, lagged unemployment (that enters linearly into $E_{t-1} u_{t}$ ) is helpful in forecasting inflation linearly. Under the version of Cukierman's model, lagged unemployment (that enters squared into $\sigma_{u, t}^{2}$ ) is helpful in forecasting inflation nonlinearly.

\footnotetext{
${ }^{8}$ Results obtained using an $\operatorname{ARIMA}(2,0,2)$ are very similar to the ones reported and are available from the author upon request.
} 
Hence, the comparison between both models is essentially the comparison between a linear and nonlinear model of the relation between inflation and (past) unemployment.

\subsection{Estimation and Results}

The joint process of inflation and unemployment was estimated by the numerical maximization of their joint log likelihood function. The system consists of the inflation equation (12) and either an $\operatorname{ARIMA}(2,0,2)$ or an $\operatorname{ARIMA}(1,1,2)$ for unemployment depending on whether one assumes that the natural rate is stationary or not. As noted above, the intention is to examine to what extent results are robust to the use of different forecasting models for the unemployment rate. Tables 2 and 3 report Full Information Maximum Likelihood (FIML) estimates of the reduced-form coefficients in (12) for the samples 1960:1 to 1999:4 and 1970:1 to 1999:4, respectively. ${ }^{9}$ Panels A and B in each Table report results for the cases where unemployment is forecasted using an $\operatorname{ARIMA}(2,0,2)$ or an $\operatorname{ARIMA}(1,1,2)$, respectively.

Column (2) reports the estimates of the most general model with asymmetric central bank preferences and an unemployment target proportional to the natural rate (that is, $0<k \leq 1$ ). This model imposes restrictions neither on preferences, nor on the proportion of the natural rate that is targeted by the central bank. The coefficient of expected unemployment $(b)$ is quantitatively small and some cases negative. In all cases, the hypothesis that this coefficient is zero cannot be rejected at standard significance levels. On the other hand, the coefficient of the conditional variance of unemployment $(c)$ is always positive and the hypothesis that its true value is zero can be rejected at the 5 percent level in three cases and at the 10 percent level in one case. Hence, it would appear that conditional variance of unemployment is statistically more important than its level in explaining US inflation.

Estimates of the Barro-Gordon model are reported in Column (1) of Tables 2 and 3. This model arises from imposing the restriction that $\gamma \rightarrow 0$ in the general asymmetric model. Then, the central banker's preferences are quadratic and the conditional variance of unemployment should have not explanatory power over the inflation rate. In terms of the reduced-form model, this restriction implies $c=0$. Notice that in all cases the unemployment coefficient is positive, as predicted by the theory, and (except in one case) statistically different from zero. These results are very similar to the ones reported by Ireland (1999) and confirm his findings using a different estimation and identification strategy.

Since the Barro-Gordon and general asymmetric models are nested, it is possible to compare them using a Likelihood Ratio (LR) test of the null hypothesis that $c=0$. Under

\footnotetext{
${ }^{9}$ Estimates of the unemployment process are not reported to save space, but they are available from the author upon request.
} 
the null, the LR statistic is distributed chi-square with one degree of freedom. The statistic is reported in Tables 2 and 3 for both samples and unemployment forecasting models. Because the statistics are above the 5 percent critical value of 3.841 in all cases, the restriction imposed by the Barro-Gordon model is rejected in favor of the general model with asymmetric preferences.

Consider now a restricted version of the asymmetric-preference model where the central banker targets the natural rate of unemployment (that is, $k=1$ ). This model implies that $c \neq 0$ and $b=0$, meaning that lagged unemployment is not helpful in predicting inflation linearly. These estimates are reported in Column (3) of Tables 2 and 3. The coefficient on the conditional variance of unemployment is positive and statistically different from zero at the 5 percent level in all cases. A LR test of the restriction that $b=0$ yields statistics that are well below the 5 percent critical value of a chi-square variable with one degree of freedom. Hence, the restriction that the central banker targets the natural rate cannot be rejected in favor the model with a below-natural unemployment target.

Recall that the reduced-form coefficients $b=\lambda \phi(1-k)$ and $c=\lambda \phi \gamma / 2$, and the structural parameters $\lambda, \phi>0$, by assumption. The finding that $\hat{b}$ is approximately zero is consistent with Blinder's observation [see Blinder (1998, p. 43)] that central banks actually target the expected natural rate of unemployment (that is, $k \simeq 1$ ). The finding that $\hat{c}$ is positive implies that the preference parameter $\gamma$ is larger than zero, meaning that the US Federal Reserve weights more heavily positive than negative unemployment deviations from the natural rate. This result could account for the finding by Dolado et al. (2000) that the Fed tends to react more strongly, in terms of changes to the Federal Funds rate, to negative than positive output gaps. The prudence motive that arises when one relaxes quadratic preferences, means that the conditional variance of unemployment is helpful in forecasting the US inflation rate.

In summary, when comparing statistically the general asymmetric model with its two special cases, results indicate that the restriction imposed by the Barro-Gordon model is rejected by the data, while the one imposed by the version of Cukierman's model is not. Hence, US inflation is better explained by a game-theoretical model where the central banker weights more severely positive than negative unemployment deviations from the expected natural rate than by the standard textbook Barro-Gordon model where the central banker has quadratic preferences and targets a rate of unemployment below the natural rate.

\section{Discussion}

The seminal papers by Kydland and Prescott (1977) and Barro and Gordon (1983) gave rise to a large theoretical literature that examines the normative and positive implications of the 
temporal inconsistency of monetary policy. In contrast, the empirical analysis of this type of game-theoretical models has been more limited. This paper tests the predictions of the basic Barro-Gordon model by constructing a well-defined alternative that relaxes assumptions about central bank preferences and the targeted proportion of the natural unemployment rate. In particular, the central banker is allowed to weight more, or less, severely positive than negative unemployment deviations from its target. Hence, in contrast to the quadratic loss function usually employed in the literature, both the sign and magnitude of a deviation can affect the central banker's loss. The general model nests the Barro-Gordon as a special case where the asymmetry preference parameter tends to zero. It also nests a version of the model proposed by Cukierman (2000) when the central banker targets the expected natural rate.

The model is estimated by FIML using quarterly US data on inflation and unemployment. Likelihood Ratio tests indicate that the restriction imposed by the Barro-Gordon model is rejected by the data but the one imposed by Cukierman's model is not. Estimates of the reduced-form coefficients are consistent with idea that the Fed targets the natural unemployment rate [as suggested by Blinder (1998)] and that it weights more heavily positive than negative unemployment deviations from its target.

Although the results reported in this paper are suggestive, they should be interpreted with caution for at least three reasons. First, the model does not allow for the long lags that monetary policy seems to take to affect inflation and output. Second, the model assumes that the central bank's preference parameters are constant throughout the sample period. However, given the changes in the composition of the Board (including its chairman) during this period, it is likely that the degree of asymmetry in preferences, the unemployment target, and/or the unemployment weight in the loss function, might have changed over the sample. For example, Cukierman (2000) argues that a possible interpretation of the US inflation rate is that during the 1970s the unemployment target was below the natural rate, while in subsequent years it was close to or at the natural rate. Third, this paper focuses on the Nash equilibrium, but other equilibrium concepts might be empirically important. For example, it seems likely that reputation plays an important role in the formulation of US monetary policy. Current and future research by the author seeks to address these observations. Still, given our limited understanding of central bankers' behavior and preferences, it is probably premature to dismiss the idea that departures from the usual linear-quadratic setup are quantitatively important in modern US monetary policy making. 
Table 1. LR Tests for Neglected ARCH

\begin{tabular}{llcccccc}
\hline \hline Squared & & \multicolumn{7}{c}{ \# of Lags } \\
\cline { 3 - 8 } Residuals & Sample Period & 1 & 2 & 3 & 4 & 5 & 6 \\
\hline \multirow{3}{*}{ Original } & $1960: 1$ to $1999: 4$ & $9.57^{*}$ & $15.47^{*}$ & $15.56^{*}$ & $16.67^{*}$ & $16.67^{*}$ & $17.05^{*}$ \\
& $1970: 1$ to $1999: 4$ & $7.45^{*}$ & $14.39^{*}$ & $14.58^{*}$ & $14.99^{*}$ & $15.19^{*}$ & $15.23^{*}$ \\
Standardized & $1960: 1$ to $1999: 4$ & 0.16 & 0.95 & 0.99 & 1.09 & 1.20 & 1.54 \\
& $1970: 1$ to $1999: 4$ & 0.23 & 0.42 & 0.44 & 1.58 & 1.99 & 6.83 \\
& & & & & & & \\
\hline
\end{tabular}

Notes: The superscripts ${ }^{*}$ and ${ }^{\dagger}$ denote the rejection of the null hypothesis of conditional homoskedasticity at the $5 \%$ and $10 \%$ significance levels, respectively. 
Table 2. FIML Estimates

Sample 1960:1 to 1999:4

\begin{tabular}{|c|c|c|c|}
\hline \multirow[b]{2}{*}{ Coefficient } & \multicolumn{3}{|c|}{ Model } \\
\hline & Barro-Gordon & $\begin{array}{c}\text { Asymmetric with } \\
0<k \leq 1\end{array}$ & $\begin{array}{c}\text { Asymmetric with } \\
k=1\end{array}$ \\
\hline & $(1)$ & $(2)$ & $(3)$ \\
\hline \multicolumn{4}{|c|}{ Panel A. Forecasting Unemployment using ARIMA(2,0,2) } \\
\hline \multirow[t]{2}{*}{$a$} & $2.27^{*}$ & $3.23^{*}$ & $3.26^{*}$ \\
\hline & $(0.80)$ & $(0.65)$ & $(0.29)$ \\
\hline \multirow[t]{2}{*}{$b$} & $0.27^{*}$ & 0.005 & \\
\hline & $(0.13)$ & $(0.11)$ & \\
\hline \multirow[t]{2}{*}{$c$} & & $7.69^{*}$ & $7.76^{*}$ \\
\hline & & $(3.33)$ & $(2.98)$ \\
\hline Log likelihood & -61.91 & -59.17 & -59.17 \\
\hline LR statistic $(H: c=0)$ & 5.48 & & \\
\hline LR statistic $(H: b=0)$ & & & 0.001 \\
\hline \multicolumn{4}{|c|}{ Panel B. Forecasting Unemployment using $A R I M A(1,1,2)$} \\
\hline \multirow[t]{2}{*}{$a$} & $2.01^{*}$ & $3.04^{*}$ & $3.08^{*}$ \\
\hline & $(0.78)$ & $(0.72)$ & $(0.35)$ \\
\hline \multirow[t]{2}{*}{$b$} & $0.31^{*}$ & 0.008 & \\
\hline & $(0.13)$ & $(0.15)$ & \\
\hline \multirow[t]{2}{*}{$c$} & & $10.07^{\dagger}$ & $10.25^{*}$ \\
\hline & & $(5.76)$ & $(4.70)$ \\
\hline Log likelihood & -66.78 & -63.37 & -63.37 \\
\hline LR statistic $(H: c=0)$ & 6.82 & & \\
\hline LR statistic $(H: b=0)$ & & & 0.0018 \\
\hline
\end{tabular}

Notes: $a$ is the intercept term, $b$ is the coefficient of expected unemployment, and $c$ is the coefficient of the conditional variance of unemployment. The figures in parenthesis are standard errors. The superscripts ${ }^{*}$ and ${ }^{\dagger}$ denote the rejection of the null hypothesis that the true coefficient is zero at the $5 \%$ and $10 \%$ significance levels, respectively. 
Table 3. FIML Estimates

Sample 1970:1 to 1999:4

\begin{tabular}{|c|c|c|c|}
\hline \multirow[b]{2}{*}{ Coefficient } & \multicolumn{3}{|c|}{ Model } \\
\hline & Barro-Gordon & $\begin{array}{c}\text { Asymmetric with } \\
0<k \leq 1\end{array}$ & $\begin{array}{c}\text { Asymmetric with } \\
k=1\end{array}$ \\
\hline & $(1)$ & $(2)$ & $(3)$ \\
\hline \multicolumn{4}{|c|}{ Panel A. Forecasting Unemployment using $A R I M A(2,0,2)$} \\
\hline \multirow[t]{2}{*}{$a$} & $2.66^{*}$ & $4.78^{*}$ & $3.49^{*}$ \\
\hline & $(1.07)$ & $(1.24)$ & $(0.33)$ \\
\hline \multirow[t]{2}{*}{$b$} & 0.26 & -0.24 & \\
\hline & $(0.16)$ & $(0.23)$ & \\
\hline \multirow[t]{2}{*}{$c$} & & $13.42^{*}$ & $10.06^{*}$ \\
\hline & & $(5.15)$ & $(3.32)$ \\
\hline Log likelihood & -53.64 & -47.16 & -47.75 \\
\hline LR statistic $(H: c=0)$ & 6.48 & & \\
\hline LR statistic $(H: b=0)$ & & & 1.80 \\
\hline \multicolumn{4}{|c|}{ Panel B. Forecasting Unemployment using $A R I M A(1,1,2)$} \\
\hline \multirow[t]{2}{*}{$a$} & $2.07^{*}$ & $3.24^{*}$ & $2.86^{*}$ \\
\hline & $(1.05)$ & $(1.11)$ & $(0.59)$ \\
\hline \multirow[t]{2}{*}{$b$} & $0.36^{*}$ & -0.08 & \\
\hline & $(0.16)$ & $(0.20)$ & \\
\hline \multirow[t]{2}{*}{$c$} & & $22.27^{*}$ & $20.14^{*}$ \\
\hline & & $(10.89)$ & $(8.65)$ \\
\hline Log likelihood & -62.20 & -56.14 & -56.22 \\
\hline LR statistic $(H: c=0)$ & 6.06 & & \\
\hline LR statistic $(H: b=0)$ & & & 0.16 \\
\hline
\end{tabular}

Notes: see notes to Table 2. 


\section{References}

[1] Barro, R. and Gordon, D. (1983), "A Positive Theory of Monetary Policy in a Natural Rate Model," Journal of Political Economy, 91: 589-610.

[2] Blinder, A. S. (1998), Central Banking in Theory and Practice, The MIT Press: Cambridge.

[3] Christoffersen, P. F. and Diebold, F. X. (1997), "Optimal Prediction Under Asymmetric Loss," Econometric Theory, 13: 808-817.

[4] Cukierman, A. (2000), "The Inflation Bias Result Revisited ," Tel-Aviv University, Mimeo.

[5] Dolado, J. J., María-Dolores, R., and Naveira, M. (2000), "Asymmetries in Monetary Policy Rules," Universidad Carlos III, Mimeo.

[6] Gerlach, S. (2000), "Asymmetric Policy Reactions and Inflation," Bank for International Settlements, Mimeo.

[7] Granger, C. W. J. and Pesaran, M. H. (1996), "A Decision Theoretic Approach to Forecast Evaluation," University of Cambridge, DAE Working Paper No. 9618.

[8] Hamilton, J. D. (1996), "This is what Happened to the Oil Price-Macroeconomy Relationship," Journal of Monetary Economics, 38: 215-220.

[9] Harvey, A. C. (1981), Time Series Models, Philip Allan Publishers Limited: Oxford.

[10] Ireland, P. N. (1999), "Does the Time-Consistency Problem Explain the Behavior of Inflation in the United States?", Journal of Monetary Economics, 44: 279-292.

[11] Kimball, M. S. (1990), "Precautionary Savings in the Small and the Large," Econometrica, 58: 53-73.

[12] Kydland, F. and Prescott, E. (1977), "Rules Rather Than Discretion: The Inconsistency of Optimal Plans," Journal of Political Economy, 85: 473-490.

[13] McCallum, B. T. (1997), "Crucial Issues Concerning Central Bank Independence," Journal of Monetary Economics, 39: 99-112.

[14] Nobay, R. A. and Peel, D. A. (1998), "Optimal Monetary Policy in a Model of Asymmetric Central Bank Preferences," London School of Economics, Mimeo. 
[15] Orphanides, A. and Wilcox, D. W. (1996), "The Opportunistic Approach to Disinflation," Federal Reserve Board, Mimeo.

[16] Pagan, A. (1984), "Econometric Issues in the Analysis of Regressions with Generated Regressors," International Economic Review, 25: 221-247.

[17] Pagan, A. and Ullah, A. (1988), "The Econometric Analysis of Models with Risk Terms," Journal of Applied Econometrics, 3:87-105.

[18] Persson, T. and Tabellini, G. (2000), "Political Economics and Macroeconomic Policy," in Handbook of Macroeconomics, edited by J. Taylor and M. Woodford. North-Holland: Amsterdam.

[19] Ruge-Murcia, F. J. (2001), "The Inflation Bias when the Central Banker Targets the Natural Rate of Unemployment," University of Montreal, CRDE Working Paper No. 22-2001

[20] Staiger, D., Stock, J. H., and Watson, M. W. (1997), "The NAIRU, Unemployment and Monetary Policy," Journal of Economic Perspectives, 11: 33-49.

[21] Tootell, G. M. B. (1994), "Restructuring, the NAIRU, and the Phillips Curve," New England Economic Review of the Federal Reserve Bank of Boston, September/October: $31-44$.

[22] Varian, H. (1974), "A Bayesian Approach to Real Estate Assessment," in Studies in Bayesian Economics in Honour of L. J. Savage, edited by S. E. Feinberg and A Zellner. North-Holland: Amsterdam.

[23] Weiner, S. E. (1993), "The Natural Rate and Inflationary Preasures," Economic Review of the Federal Reserve Bank of Kansas City, 79: 5-9.

[24] Zellner, A. (1986), "Bayesian Estimation and Prediction Using Asymmetric Loss Functions," Journal of the American Statistical Association, 81: 446-451. 